\title{
Degradation of nanostructured bainitic steel under rolling contact fatigue
}

\author{
W. Solano-Alvarez ${ }^{\mathrm{a}}$, E. J. Pickering ${ }^{\mathrm{a}}$, H. K. D. H. Bhadeshia ${ }^{\mathrm{a}}$ \\ ${ }^{a}$ Materials Science and Metallurgy, University of Cambridge, U.K
}

\begin{abstract}
The consequences of rolling contact fatigue on carbide-free nanostructured bainite intended for bearing applications are presented for the first time. Tests performed at various intervals followed by mechanical, microscopical, and crystallographic characterisation lead to the conclusion that the degradation mechanism is ductile void formation at interfaces, followed by growth and coalescence into larger voids that lead to fracture along the direction of the softer phase. This is different from the conventional damage mechanism that involves crack initiation at inclusions and propagation, for example in typical bearings steels such as 52100. The huge density of interfaces in the nanostructure allows the formation of a large dispersion of voids, and ultimately cracks, at depths consistent with the maximum orthogonal shear stress which occurs below the contact surface. This study should prove useful for the eventual usage of nanostructured bainitic steels in rolling bearings.
\end{abstract}

Keywords: nanostructured bainite, rolling contact fatigue, structural degradation, nanocracks, void formation

\section{Introduction}

It is possible that nanostructured bainite, which consists of incredibly fine platelets of bainitic ferrite dispersed in matrix of carbon-enriched retained austenite [1, 2], may prove suitable for the manufacture of bearings. The steel in its transformed condition can have a hardness in the range 600-670 HV, 
strength exceeding $2 \mathrm{GPa}$, and toughness levels of around $30-40 \mathrm{MPam}^{1 / 2}$; the available information on such mechanical property data is summarised in recent reviews [3-5]. The material is commercially available as armour but it also exhibits excellent abrasive and rolling-sliding wear resistance [6-14]. When the austenite content exceeds the percolation threshold, the structure resists the penetration of hydrogen [15]. The fatigue resistance in a variety of uniaxial tests has been proven to be excellent $[11,14,16]$. However, in the context of bearings, the stresses involved in fatigue due to repeated contact stresses are quite different from uniaxial loading, a close approximation being a combination of mean, uniaxial compressive-stress and torsion that are in phase with respect to their maximum values [17, 18]. The purpose of the present work was therefore to investigate the rolling contact fatigue phenomena associated with nanostructured bainite. The damage mechanisms have never before before been reported and are unlikely to be identical to common bearing steels due to the complete absence of carbides, and the work hardening mechanism associated with the retained austenite.

\section{Experimental Methods}

\subsection{Material and sample preparation}

The alloy was produced by Tata Steel UK as an ingot subjected to electroslag remelting, vacuum arc remelting, annealing, cold straightening, smooth turning, and rolling to a shaft $180 \mathrm{~mm}$ in diameter with the composition described in table 1.

Table 1: Chemical composition, wt\%, of the steel studied.

\begin{tabular}{cccccccccccccc}
\hline $\mathrm{C}$ & $\mathrm{Mn}$ & $\mathrm{S}$ & $\mathrm{P}$ & $\mathrm{Si}$ & $\mathrm{Al}$ & $\mathrm{Cu}$ & $\mathrm{Cr}$ & $\mathrm{Ni}$ & $\mathrm{Mo}$ & $\mathrm{V}$ & $\mathrm{Nb}$ & $\mathrm{Ti}$ & $\mathrm{B}$ \\
\hline 0.8 & 2.03 & 0.006 & 0.006 & 1.51 & 0.057 & 0.03 & 0.22 & 1.05 & 0.377 & 0.004 & 0.007 & 0.019 & 0.0007 \\
\hline
\end{tabular}

Long cylindrical samples $9.53 \mathrm{~mm}$ in diameter and $120 \mathrm{~mm}$ long were cut out along the longitudinal direction of the shaft using a band saw, turned, ground, and polished to a $1 \mu \mathrm{m}$ finish. These were designed for the rolling contact fatigue testing machine described later. 


\subsection{Heat treatment}

Samples were wrapped in four layers of steel foil and austenitised in a Carbolite RWF1200 box furnace at $930^{\circ} \mathrm{C}$ for $30 \mathrm{~min}$, cooled in air to $250^{\circ} \mathrm{C}$ which took around $6 \mathrm{~min}$, introduced to an oven for isothermal heat treatment at $200^{\circ} \mathrm{C}$ for 10 days, and cooled in air. In order to corroborate if the heat treatment was successful, one of the samples was cut along the radial cross section and prepared for macro-hardness testing and metallographic characterisation.

\subsection{Rolling contact fatigue (RCF) testing}

Testing of the cylindrical samples was carried out on a Delta Research Corporation BR-4 Ball-Rod Rolling Contact Fatigue machine [19]. In this machine, the load is applied by three $12.7 \mathrm{~mm}$ in diameter balls, placed inside a bronze retainer, so that the balls push against the rotating cylindrical test specimens through two tapered bearing cups held at a certain distance of each other by adjusting the length of three springs, as seen in fig. 1. Testing was performed at room temperature without transient conditions or hydrogen charging of the specimens that would accelerate, but might also alter the microstructural degradation process.

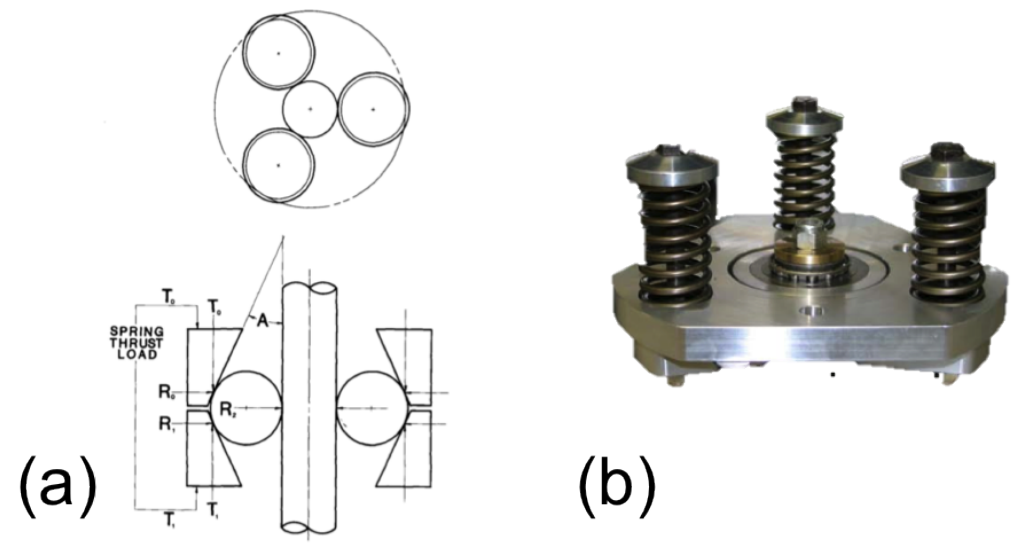

Figure 1: a) Rotating cylindrical specimen stressed by three radially-loaded balls, which are thrust loaded by three compression springs [20], and b) individual retainer plate during the load-setting configuration showing the three compression springs around three calibration bolts. After [21]. 
Before every test, three new 52100 balls with a surface roughness of $0.013 \mu \mathrm{m}$, the bronze retainer, and the rod specimen were ultrasonically cleaned for $5 \mathrm{~min}$ first in a mixture of $50 \%$ isopropanol-50\% water, then in acetone, and finally in isopropanol. The tapered loading cups were changed every four tests and turbine oil BP2380 was used as a lubricant at room temperature and a rate of 10 drops $\min ^{-1}$. This oil was filtered and recirculated. Vibration levels were monitored through an accelerometer, which automatically stopped tests if the thresholds were surpassed, caused normally only by flaking or spalling. All tests were performed at a rotational speed of $3600 \mathrm{rpm}$ (the design of the test rig allows $\sim 2.4$ stress cycles per revolution) and a Hertzian pressure of $3.5 \mathrm{GPa}$ (191 N of load). The values and depths of the maximum unidirectional and orthogonal shear stresses induced by such Hertzian pressure are presented in table 2; the actual stresses experienced are likely to be somewhat smaller given groove formation. how does the diameter of the 2-D elastic contact area compare with the groove profiles that are recorded later?

Table 2: Maximum shear stress, $\tau_{\max }$, acting at $\pm 45^{\circ}$ with respect to the surface, and orthogonal shear stress $\tau_{x z, \max }$, acting parallel and normal to surface, and their depths, for a 2-D circular contact. The values assume frictionless and elastic Hertzian contact at $3.5 \mathrm{GPa}[22]$.

\begin{tabular}{lcccc}
\hline & \multicolumn{2}{c}{$\tau_{\max }$} & \multicolumn{2}{c}{$\tau_{x z, \max }$} \\
& GPa & Depth $/ \mu \mathrm{m}$ & GPa & Depth $/ \mu \mathrm{m}$ \\
\hline Circular contact & 1.09 & 190 & 0.88 & 99 \\
\hline
\end{tabular}

\subsection{Characterisation}

\subsubsection{Surface roughness}

After extracting the samples from the RCF equipment, the profile of the wear track in the longitudinal direction of the cylindrical test specimens was measured with a Veeco Dektak 6M Stylus Profiler, which has a tip radius of $12.5 \mu \mathrm{m}$. 


\subsubsection{Microhardness profile}

The Vickers micro-hardness profile of the surface up to a depth of $\sim 1 \mathrm{~mm}$ using a load of $1 \mathrm{~kg}$ was performed on a new and a used ball cut in half and on the cylindrical test samples cut along the radial cross section at the centre of the wear track after RCF testing.

\subsubsection{Microstructural characterisation}

In order to study the microstructural degradation of nanostructured bainite after RCF as well as understanding the reason of the test failure, the unetched and etched $(2 \% \mathrm{Nital})$ microstructure and surface of the balls (used and new) and cylindrical test specimens were characterised using a Zeiss optical microscope, an Olympus Stereo microscope, and a JEOL JSM 5500LV scanning electron microscope (SEM) equipped with an energy dispersive $\mathrm{x}$ day spectroscopy (EDS) detector. For such characterisation, RCF specimens were cut along the centre of the racetrack in the radial cross section. More detailed characterisation of the longest lasting RCF sample was performed by carving out lamellae using a focused ion beam (FIB) in a FEI Helios dual beam field emission SEM. These lamellae were then observed using a JEOL 200CX transmission electron microscope (TEM).

\subsubsection{X-Ray diffraction}

The volume fractions of the phases present after heat treatment and after the longest running RCF test were determined using a Philips PW1830 vertical diffractometer with a $\mathrm{CuK}_{\alpha}$ radiation. Scans were performed from 30 to $125^{\circ}$, with a step size of $0.05^{\circ}$ and a dwell time of $26 \mathrm{~s}$. A divergence

slit of $0.5^{\circ}$, an anti-scatter slit of $0.5^{\circ}$, and a receiving slit of $0.2 \mathrm{~mm}$ were used to restrict the beam size and the counts obtained.

To account for a possible stress-induced transformation of retained austenite into martensite in the sample under RCF, High Score plus and the Rietveld refinement method were used to fit austenite to three isolated austenite peaks: 002, 022, and 113. The maximum and minimum estimates for the lattice parameter of austenite could then be obtained, which were then used to calculate its carbon concentration through the Dyson and Holmes equation [23]. Since this carbon concentration is inherited by the stress-transformed 
BCT martensite, its maximum and minimum values of tetragonality were obtained by referring to the Honda and Nishiyama charts [24]. These lattice parameters $\left(a_{\gamma}, a_{\alpha^{\prime}}\right.$, and $\left.c_{\alpha^{\prime}}\right)$ were used to fit martensite, retained austenite, and bainitic ferrite to either the whole spectrum or a cropped version of it, which eliminated martensite and austenite overlapping peaks (e.g. $110_{\alpha^{\prime}}$ and $\left.111_{\gamma}\right)$.

\section{Results and Discussion}

\subsection{Heat treatment}

After heat treatment, the sample consisted of a typical structure of fine ferritic plates and intervening austenite films as seen in fig. 2. The sample had an average hardness and standard error of $632 \pm 2 \mathrm{HV} 30$ corresponding to ten indentations. I deleted "carbides" because I do not see any evidence in Fig. 2 and indeed, they should not be there. Quantitative measurements of the phase fractions are presented later.

(a)

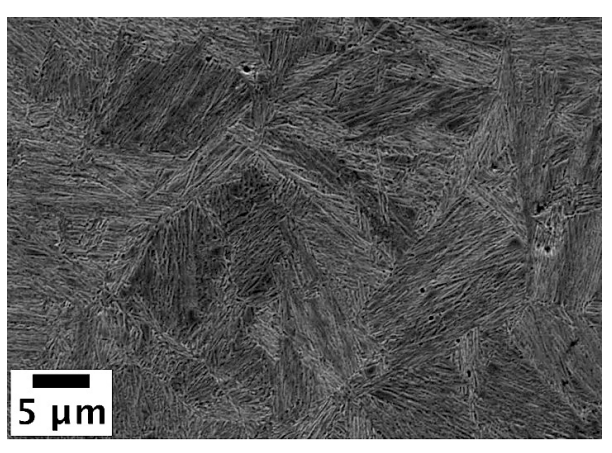

(b)

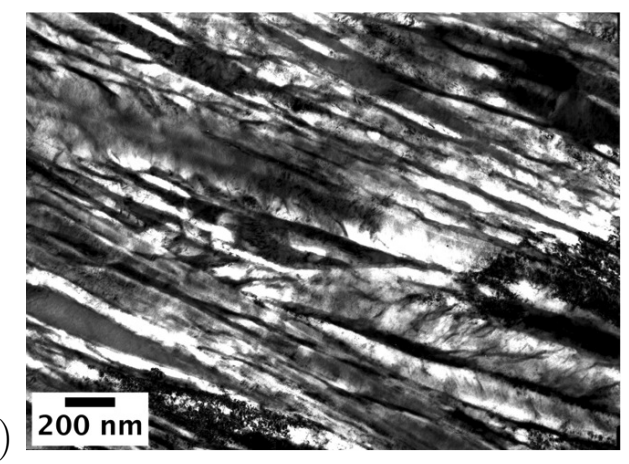

Figure 2: Nanostructured bainite formed after austenitisation at $930^{\circ} \mathrm{C}$ for $30 \mathrm{~min}$ and isothermal heat treatment at $200^{\circ} \mathrm{C}$ for 10 days in a) scanning electron micrograph and b) transmission electron micrograph.

\subsection{Rolling contact fatigue}

The results of the RCF tests are listed in table 3. The number of cycles is given by the product of the time, revolutions per minute, and a factor of 2.4. The latter factor comes from the number of stress cycles between balls and 
specimen for one revolution of the specimen, given that the balls and sample have different diameters [20]. All five samples ran until the accelerometer of the rig automatically stopped the tests when a set threshold level of vibration was exceeded, caused not by the failure of the sample but by unintended failure of the lubrication system. Nevertheless, the times at which these tests were automatically stopped, proved to be very useful in determining the progressive degradation of the nanobainitic structure underneath the contact surface. All samples were characterised except that from test 2 where the number of cycles is similar to that of sample 3 . Note the nanobainite is not a MICROstructure

Table 3: RCF cycles for nanobainitic samples running at room temperature, $3600 \mathrm{rpm}$, and $3.5 \mathrm{GPa}$ of Hertzian pressure. In the case of the sample identified with a $\dagger$, one of the balls did not follow the track by the other two balls, so the deepest groove formed by testing will have experienced two-thirds of the cycles quoted.

\begin{tabular}{lcc}
\hline Test & Cycles & Time / h \\
\hline 1 & $2.1 \times 10^{7}$ & 41 \\
2 & $1.2 \times 10^{8}$ & 226 \\
3 & $1.3 \times 10^{8}$ & 252 \\
4 & $2.3 \times 10^{8} \dagger$ & 450 \\
5 & $4.9 \times 10^{8} \dagger$ & 948 \\
\hline
\end{tabular}

The profile analysis of the contact grooves has identified two cases: an even distribution of the load with a single wear track (fig. 3a and b), and that were two parallel tracks are formed, separated $450 \mu \mathrm{m}$ in the case of fig. $3 \mathrm{c}$ and $\mathrm{d}$. In the latter case, the depths of the grooves indicate that the tracks are traversed by either one ball (shallow groove) or two balls, so that the number of cycles experienced will at most be two-thirds of those listed in Table 3. In you microstructural studies, do you examine the structure under the two ball groove or the shallower one?

After cutting a new and a used ball of the longest running test, as well as the test samples along the radial cross section at the centre of the deepest wear track, the hardness of the material below the contact surface was characterised, fig. 4 . The hardness indents, each about $55 \mu \mathrm{m}$ across the corners, were placed in parallel arrays inclined to the surface in order to avoid interference between indents. However, it is not possible to obtain reliable hardness values within about $150 \mu \mathrm{m}$ from the surface since the plastic zone 
(a)

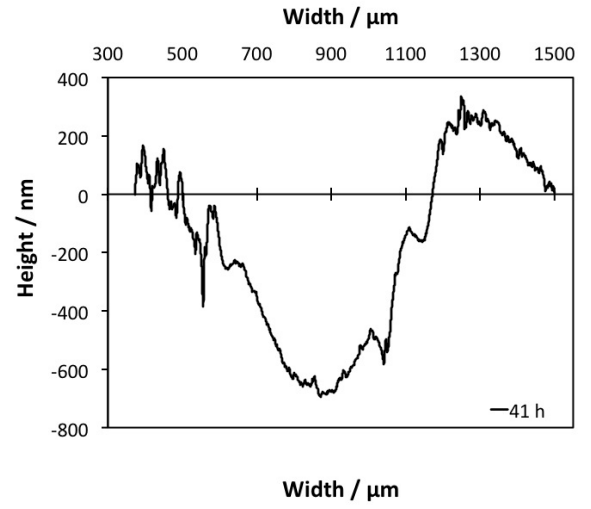

(c)

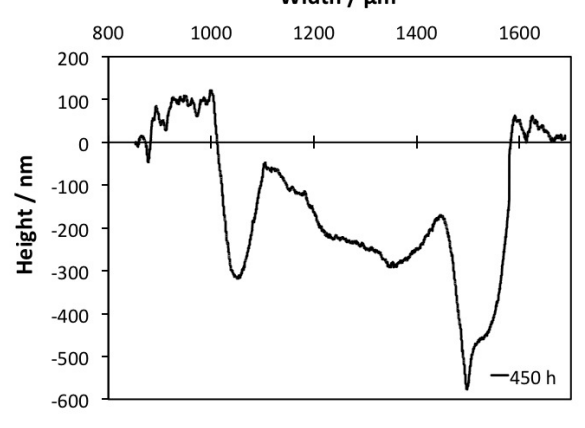

(b)

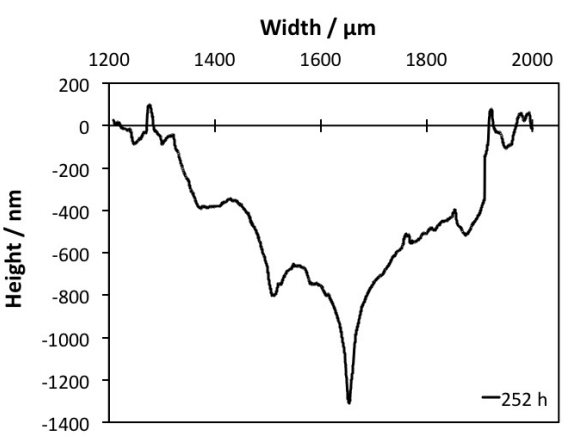

$(d)$

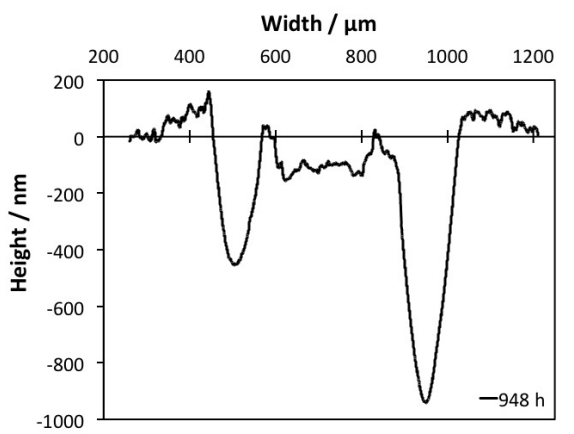

Figure 3: Profiles of the contact grooves for each of the different samples tested: a) $41 \mathrm{~h}$, b) $252 \mathrm{~h}$, c) $450 \mathrm{~h}$, and d) $948 \mathrm{~h}$. These graphs should all be on the same scales. 
of each indent extends about three times the indent size [25]. The results show that there is some hardening of the balls as a result of testing, but not much of a change with the bainitic rods. Note that only the rods with the single tracks are illustrated; tests have been done on the other rods but the hardness values are found to be similar, though they may not be reliable due to the multiple wear-tracks.

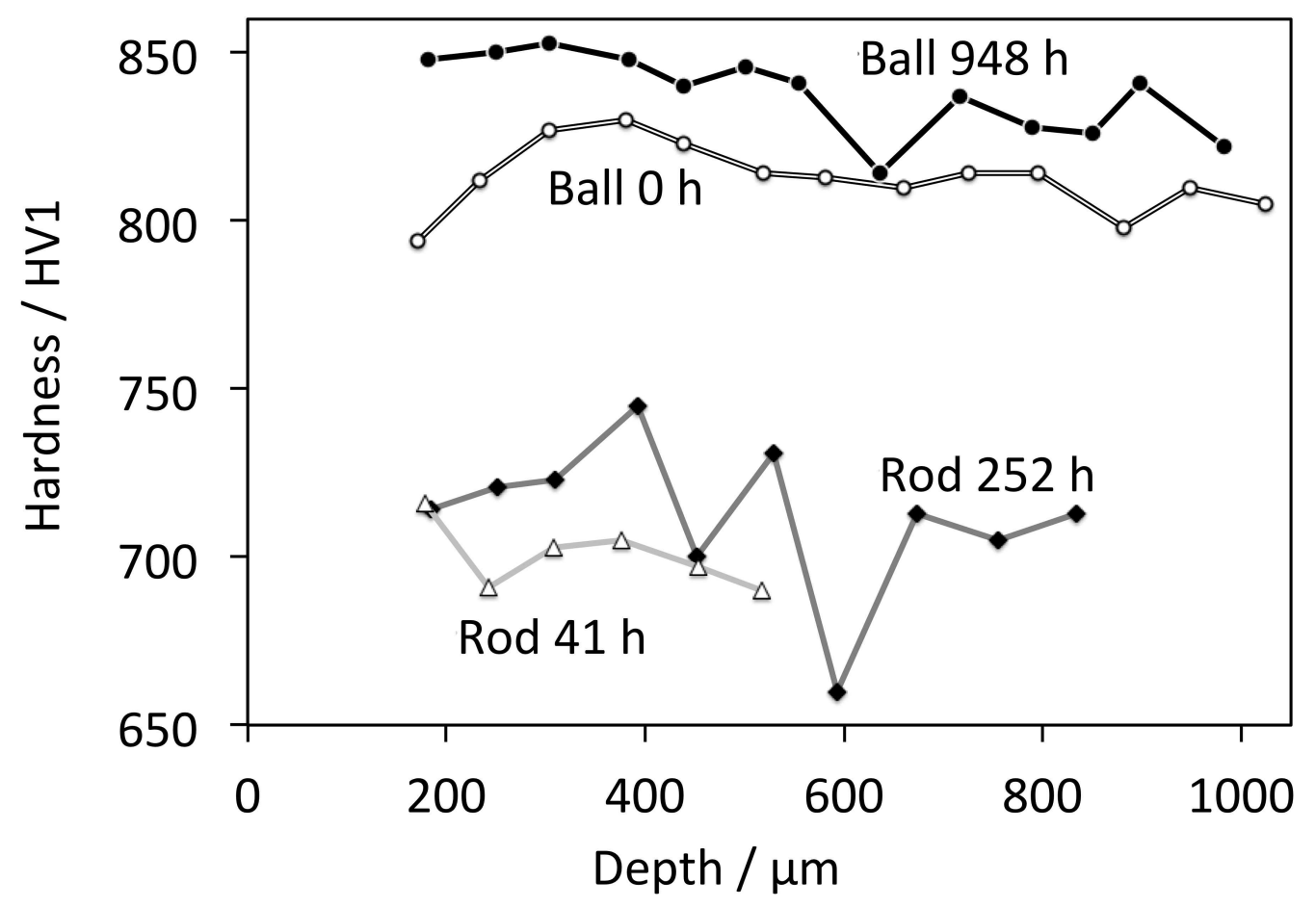

Figure 4: Microhardness profile of the subsurface of balls and samples tested under RCF.

\subsubsection{Balls}

The microstructure of the new ball consists of a fine tempered martensite with an even distribution of proeutectoid cementite as shown in fig. 5, whereas the surface is polished to a nominal roughness of $0.013 \mu \mathrm{m}$ and displays only a few shallow scratches. After $948 \mathrm{~h}$ of RCF under a Hertzian pressure of $3.5 \mathrm{GPa}$, all three balls displayed several contact grooves in random orientations denoting free movement of the ball within the bronze cage. In theory, at least three grooves should be seen on each ball, all parallel to 
each other due to contact with the upper cup, the sample, and lower cup if there is a fixed rotational axis, parallel to the rotational axis of the test specimen. Although the grooves are signs of considerable material flow, there were no pits or cavities from flaked material of the balls that could have been indented into the surface of the test sample causing surface cracks. The microstructure below the contact grooves shows no signs of degradation apart from debonded inclusions and a run-in surface.

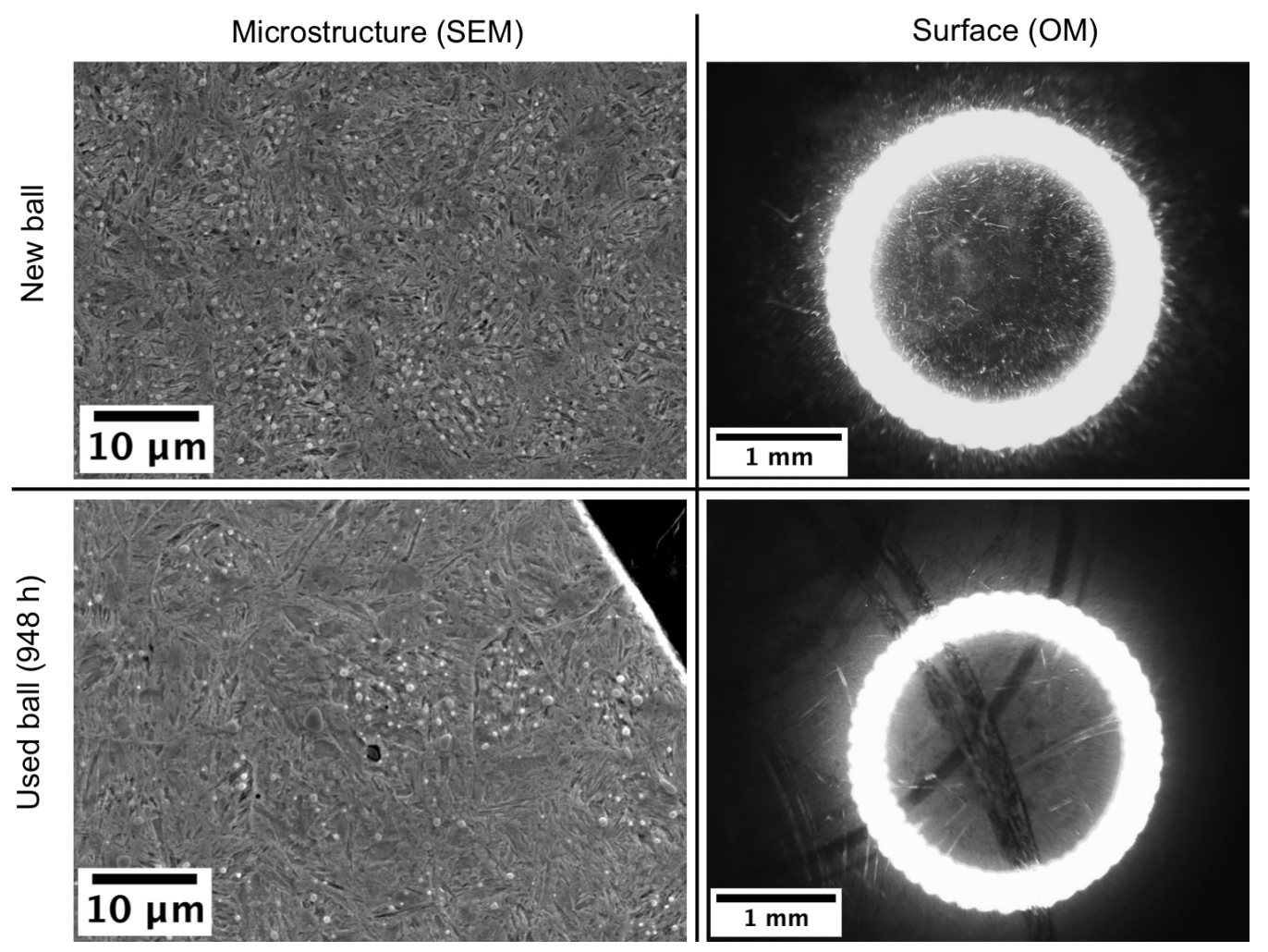

Figure 5: Microstructure and surface of a new and used ball after RCF.

\subsubsection{Test specimens}

The unetched and etched (nital) microstructure of the test specimens that run for different times under RCF was characterised using $\mathrm{OM}$ and SEM. As seen in fig. 6(a,b), the $41 \mathrm{~h}$ sample displays an infrequent distribution of clouds of tiny voids, marked by white arrows, that are sometimes located around inclusions. Large inclusions debonded from the matrix and 
some of them that were identified using EDS to be a duplex aluminium and magnesium oxide, developed crack morphologies reminiscent of "butterflies" $[26,27]$, although without the classical white-etching wings.

More severe damage developed with time; the $252 \mathrm{~h}$ in (c), (d), and (e) shows a larger distribution of these clouds of voids, which were more severe around debonded inclusions, as marked by the white arrows, but also present in less intensity away from them. The area around these voids shows also a darker etching response than the matrix in the SEM so the chemical composition was studied through

In the sample tested for $450 \mathrm{~h}$ a large collection of cracks up to a depth of $\sim 85 \mu \mathrm{m}$ was found in directions parallel and perpendicular to the contact surface, fig. 7(a,b). This depth is consistent with the location of the maximum orthogonal shear stress at $99 \mu \mathrm{m}$, and is consistent with the literature [28]. How did you calculate the 99 micrometres? As will be demonstrated later, these cracks appear to form as result of the coalescence of the families of voids shown in the $41 \mathrm{~h}$ and $252 \mathrm{~h}$ samples. After $948 \mathrm{~h}$, there is a very significant dispersion of these void-cracks in the subsurface of the sample, growing to some $60 \mu \mathrm{m}$ in length, fig. $7(\mathrm{c}, \mathrm{d})$. Their growth seems to be driven by the absorption of continuously formed voids and guided to deflect damage by branching, normally in perpendicular directions as shown by the white arrow in (d), a mechanism that has been exploited to toughen brittle materials [29].

In order to study the mechanism of void-crack formation, two different crack-types were examined in detail. For this purpose, maples were carved out as lamellae using a FIB SEM and characterised using transmission electron microscopy. Fig. 8(a) shows a crack that has originated from a cluster of voids. As seen in fig $8 \mathrm{~b}$, there are numerous minuscule voids between $1-60 \mathrm{~nm}$ in size, at a depth of $2.5 \mu \mathrm{m}$ below the gross damage illustrated in Fig. 8(a). Furthermore, there are fine cracks (about $7 \mathrm{~nm}$ thick) associated with the voids, and electron diffraction indicated that the whole region did not contain any retained austenite.

The branching morphology described earlier is the second type of crack characterised. The same phenomenon is seen below the branched crack in fig. 9, where the layers of austenite and ferrite lose structure and blend into one dark homogenised ferritic phase around the voids. It can be seen in fig. $9 \mathrm{~d}$ 

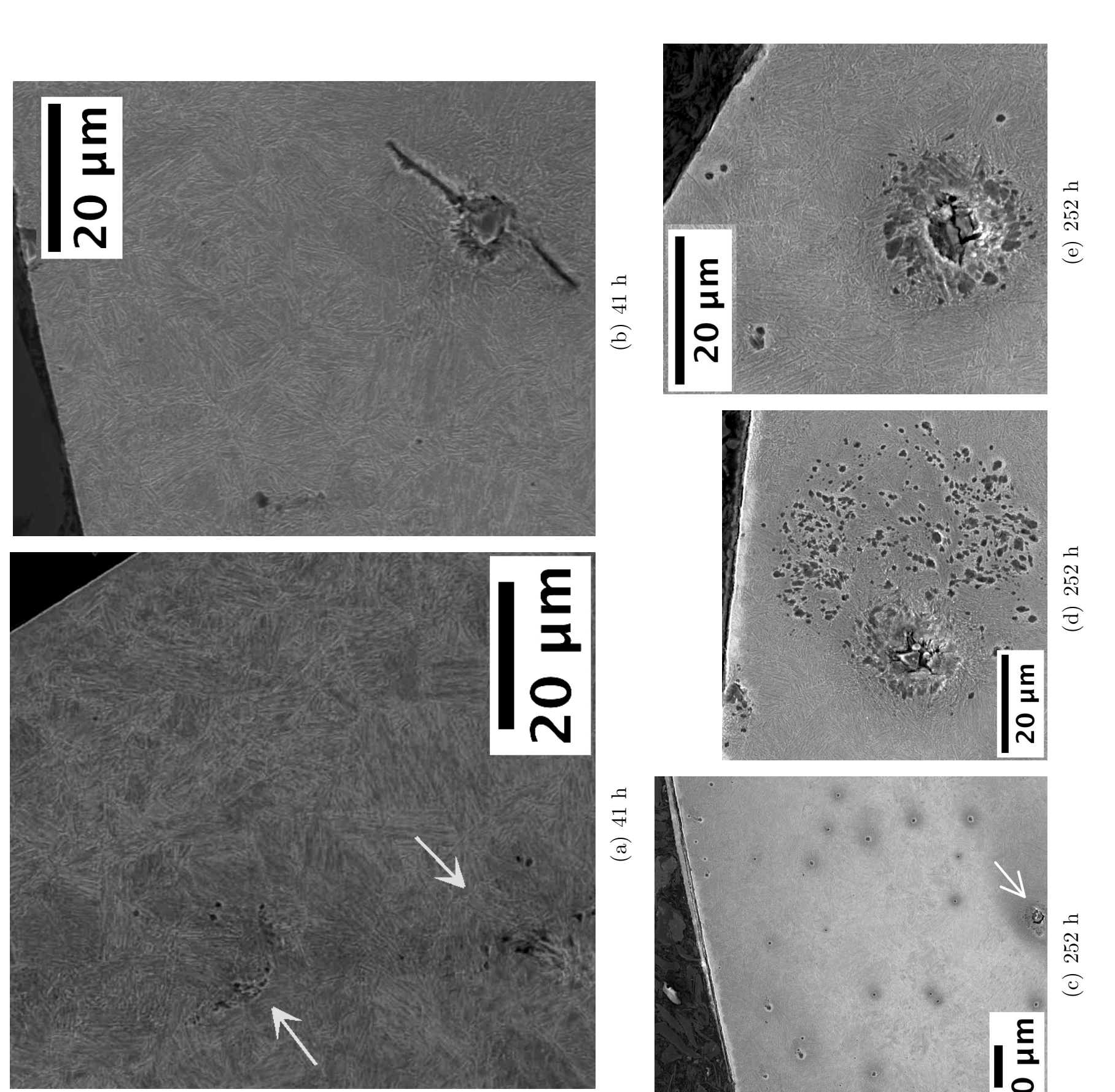

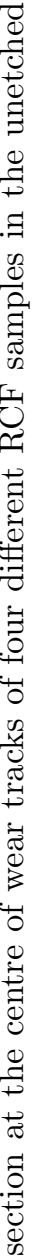

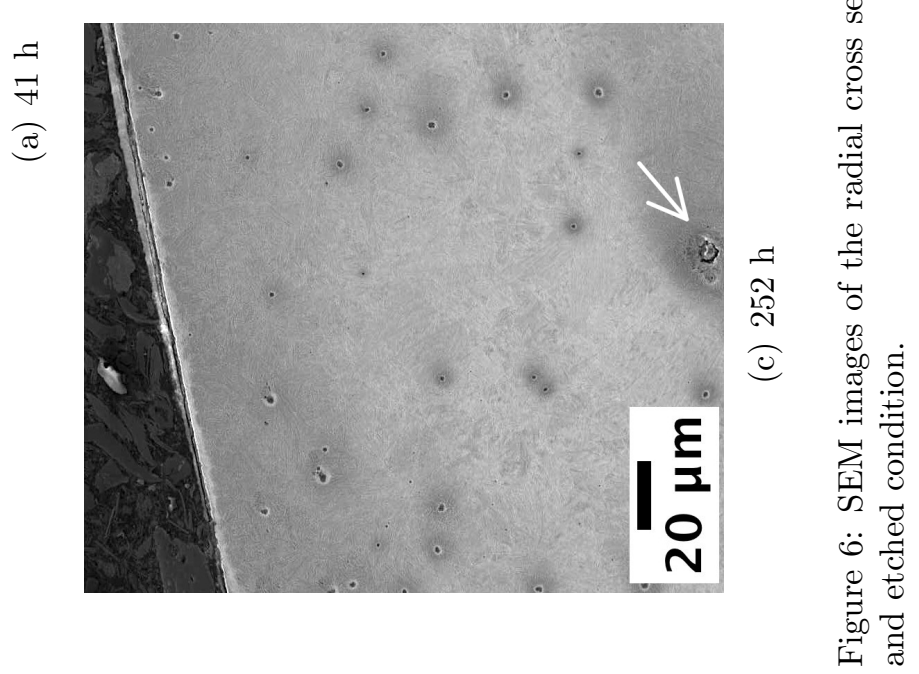



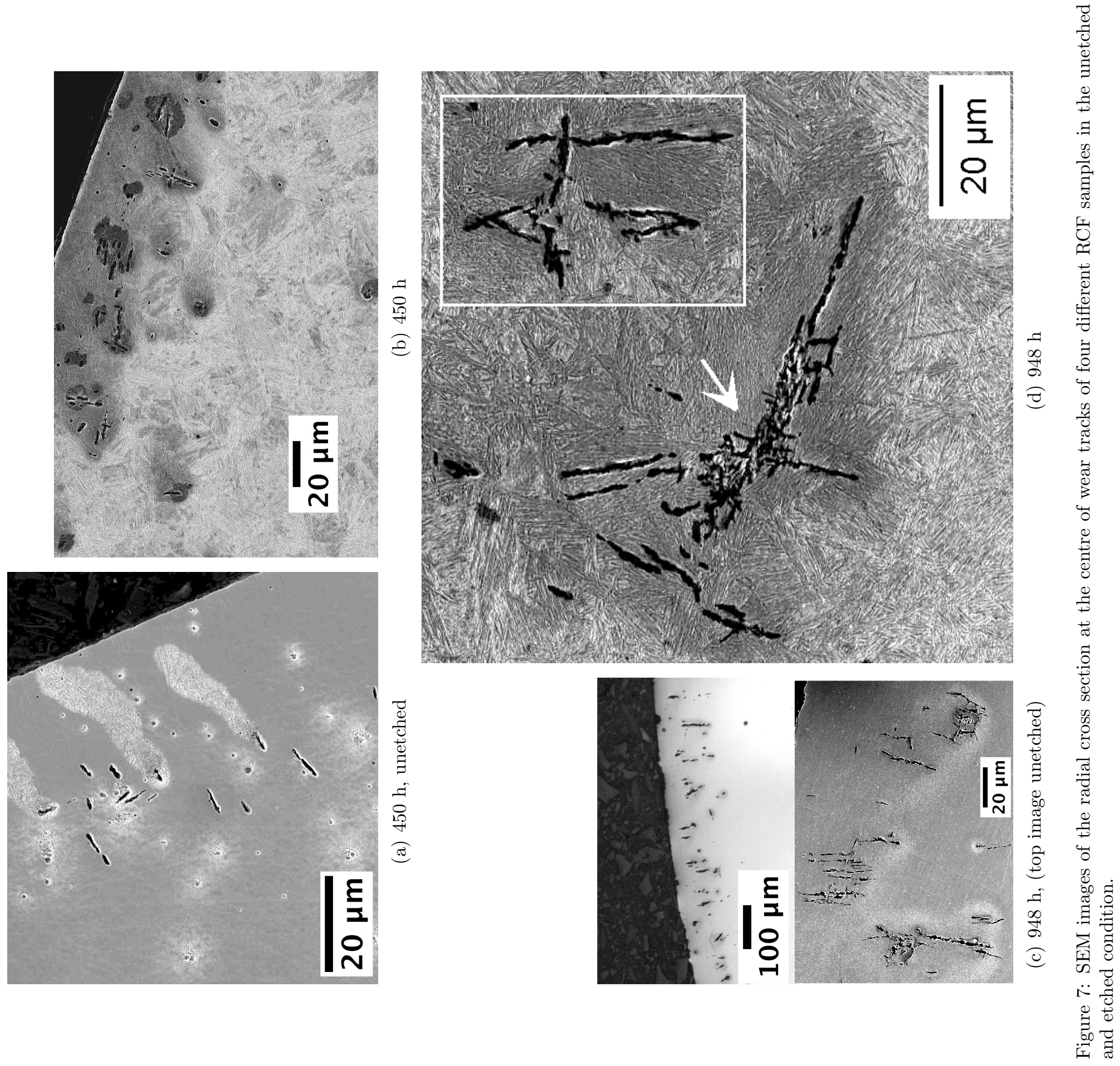
that a void (arrowed) is formed in what appears to be the interface between a blocky retained-austenite region transformed into martensite and a platelet of bainitic ferrite, with a fine crack confined within the softer ferrite. Electron diffraction verified the absence of blocky austenite in the regions of maximum subsurface shear-stresses, suggesting its deformation-induced transformation to untempered martensite. However, the thin layers of retained austenite were still present as seen in fig. $9(\mathrm{e})$, which corresponds to the exact same region as fig. $9(\mathrm{~d})$ after a slight tilt of the sample. The main void is still present as marked by the white arrow.

The evidence presented above suggests that the failure mechanism in nanostructured bainite under rolling contact fatigue is ductile void formation at the interfaces, for example between martensite and bainitic ferrite sheafs or between ferrite and austenite layers due to dislocation pile-up and compatibility requirements at the interface breaking down causing decohesion [30, 31]. It is well known in the context of dual phase steels [32-35], that ductile voids form at the interface between hard martensite and soft ferrite. In the present case it is of course the larger regions of carbon-enriched retained austenite that transform into hard martensite first, in order to create the strain incompatibility. But in principle, this could be the achilles heal of the material in rolling contact fatigue, because unlike normal bearing steels the fine scale structure will be mechanically heterogeneous if the austenite is not stable.

It is also observed that when a crack actually forms, it can lengthen within the bainitic ferrite when the latter is adjacent to the harder phase (fig. ??; the consequence of this on the overall performance of the material is not clear. On the other hand, the mechanisms of damage observed are radically different from those present in classical bearing steels such as the 52100 steel, the details of which have been reviewed elsewhere [27].

\subsubsection{X-ray Diffraction}

The XRD results of a sample after heat treatment $(0 \mathrm{~h})$ and after $\mathrm{RCF}$ (948 h) summarised in table 4 confirm the stress-induced transformation of some small amount of retained austenite to martensite after RCF. How-

ever, the X-ray beam used covers the whole area of the sample $\left(39 \mathrm{~mm}^{2}\right)$, whereas the decomposition of austenite would only occur in the region of 


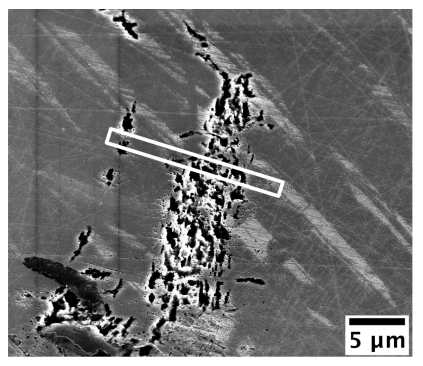

(a) Location of FIB sample

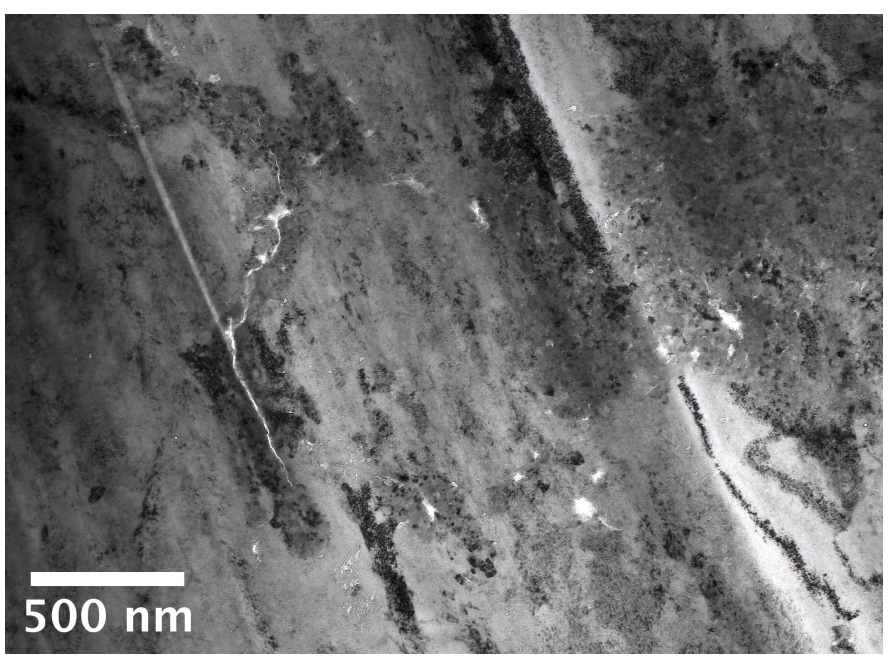

(b) Microscopic voids

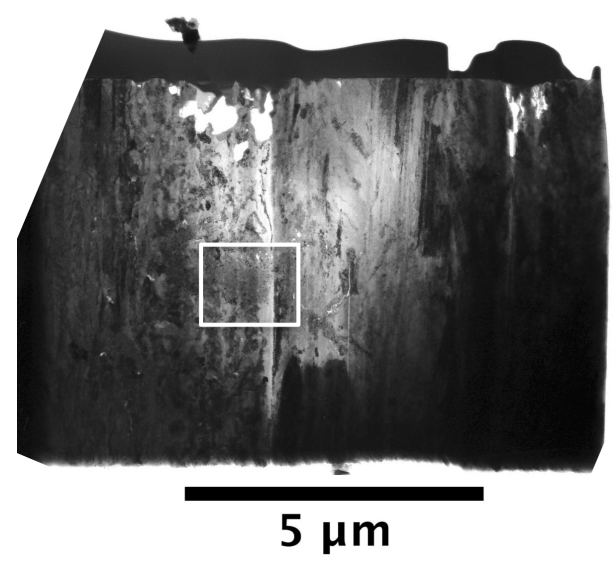

(c) Location of image shown in (b)

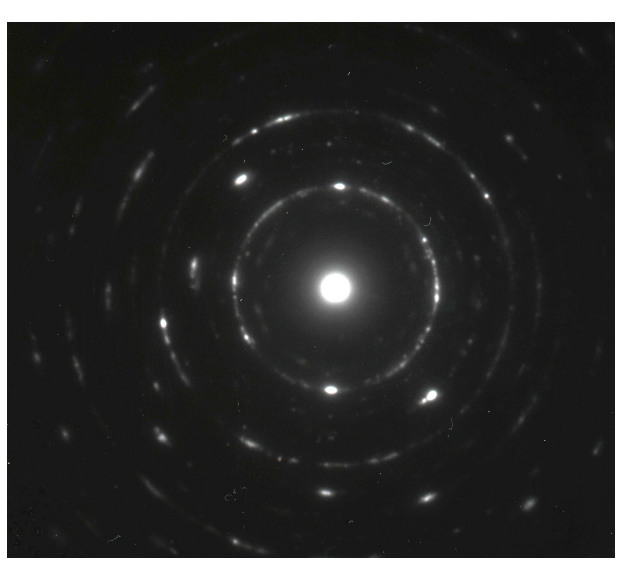

(d) Electron diffraction

Figure 8: Images from a crack that has evolved from microscopic voids in the sample that clocked $948 \mathrm{~h}$. (a) Shows the location of the region from which a sample was extracted for transmission electron microscopy. (b) Transmission electron micrograph illustrating microscopic voids and fine cracks associated with the voids, from a region well below the gross cracking. (c) The rectangle corresponds to the micrograph in (b). (d) Electron diffraction pattern showing the absence of any austenite. 


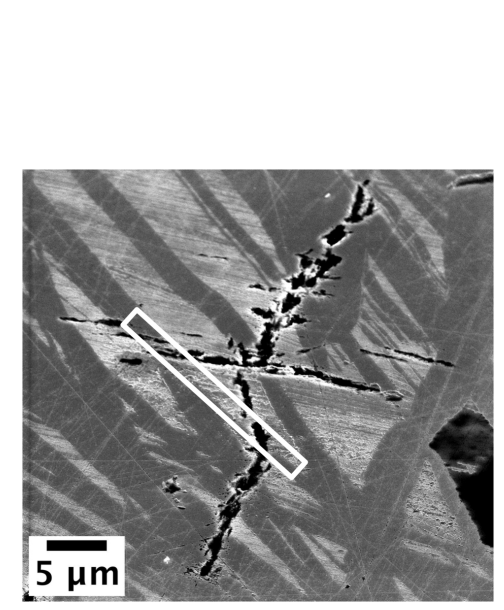

(a) Location of FIB sample

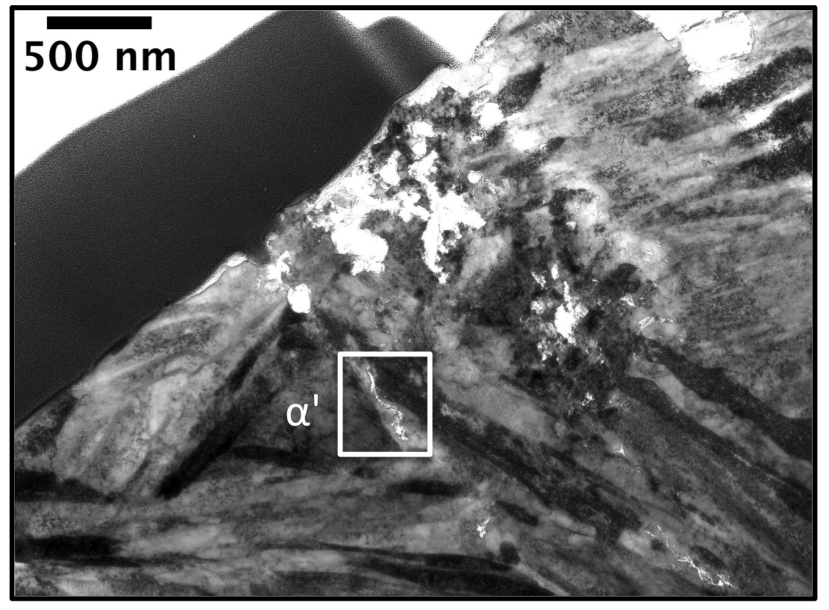

(b) Region examined in (c)

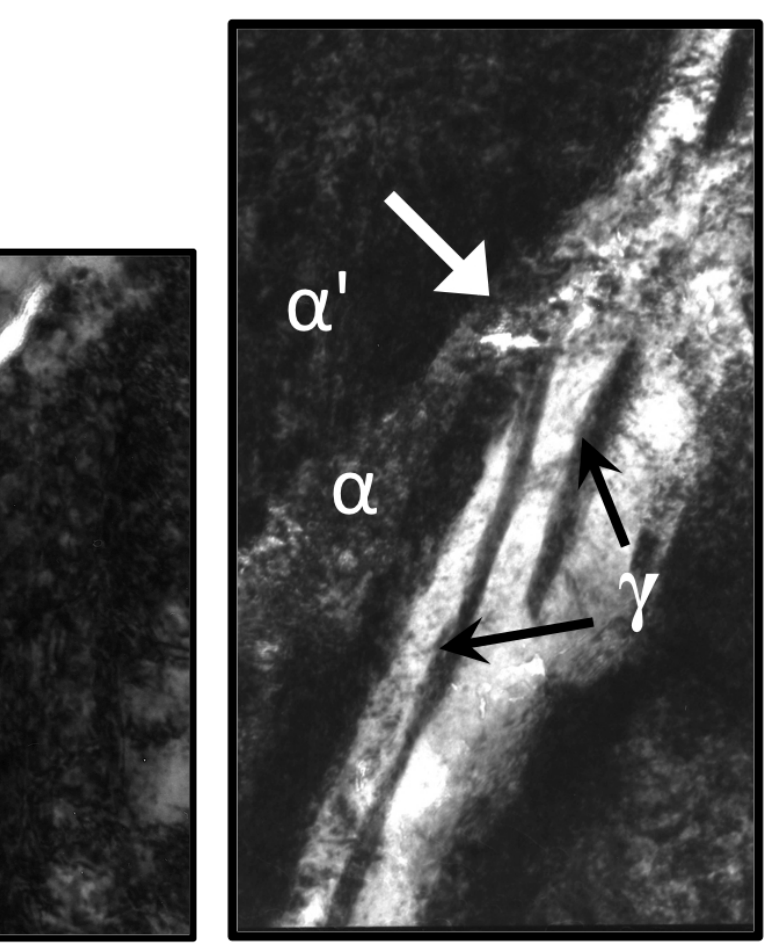

(d) Films of austenite (c) Void and crack

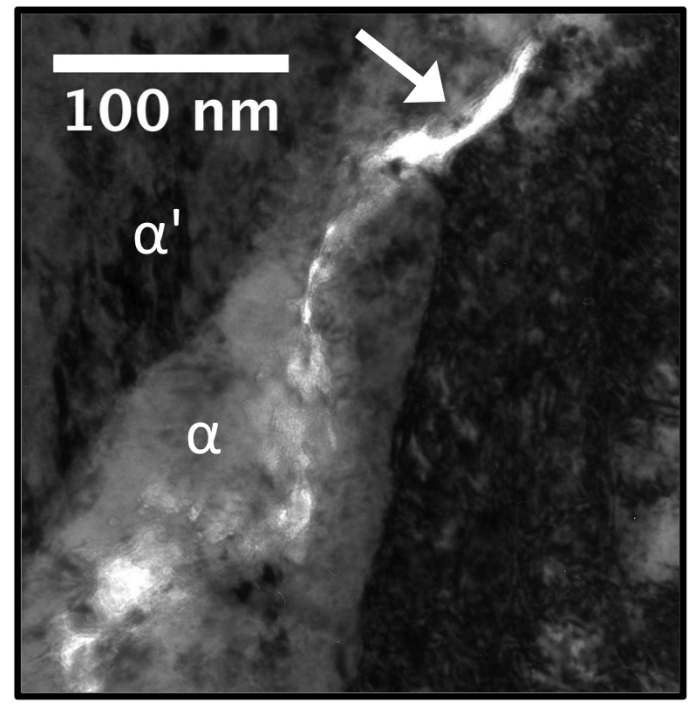

Figure 9: Images from a branched crack that has evolved from microscopic voids in the sample that clocked $948 \mathrm{~h}$. (a) Shows the location of the region from which a sample was extracted for transmission electron microscopy. (b) The rectangle marks the region examined with transmission microscopy. (c) Void at prior- $\gamma / \alpha$ interface and crack inside the bainite. (d) Same region as (c) but with the foil tilted. 
maximum subsurface shear stresses, which represents an area of maximum $3.7 \mathrm{~mm}^{2}(0.25 \mathrm{~mm}$ thick all along the circumference of the half-disc sample of $9.53 \mathrm{~mm}$ in diameter) leading to an averaging [36]. Nevertheless, TEM imaging and diffraction patterns of the regions of maximum subsurface shear stress (fig. 8) confirm only decomposition of blocky retained austenite, but not of the austenite films.

Table 4: Volume fraction of bainitic ferrite $\left(V_{\alpha}\right)$, retained austenite $\left(V_{\gamma}\right)$, and stressinduced martensite $\left(V_{\alpha^{\prime}}\right)$ for nanobainitic samples after 0 and $948 \mathrm{~h}$ of RCF. The error to all volume fractions is \pm 0.01 .

\begin{tabular}{llccc}
\hline & & \multicolumn{3}{c}{ Sample } \\
Analysis method & Phase fraction & $0 \mathrm{~h}$ & $948 \mathrm{~h}$ \\
& & $V_{\alpha}$ & 0.779 & 0.761 \\
& $V_{\gamma}$ & 0.213 & 0.209 \\
austenite lattice parameter deduced & $002_{\gamma}, 022_{\gamma}$, and $113_{\gamma} ;$ all peaks & 0.008 & 0.030 \\
$\begin{array}{l}\text { (including those that overlap) used to } \\
\text { determine volume fractions }\end{array}$ & $V_{\alpha}^{\prime}$ & & \\
\hline $\begin{array}{l}\text { austenite lattice parameter deduced } \\
\text { from 002 }\end{array}$ & $V_{\alpha}$ & 0.802 & 0.796 \\
overlapping peaks used to determine & $V_{\gamma}$ & 0.198 & 0.183 \\
volume fractions & $V_{\alpha}^{\prime}$ & 0 & 0.021 \\
\hline
\end{tabular}

\section{Conclusions and Summary}

The following conclusions can be drawn about the rolling contact degradation of nanostructured bainite:

- The damage mechanism found is quite different from that observed in conventional bearing steels such as 52100. In particular, void formation is prominent, and the linking of these voids represents a key mechanism of damage evolution.

- The indications are that voids form at interfaces between regions of martensite and bainitic ferrite. The martensite here originates from the deformation-induced transformation of relatively coarse regions of austenite. It is safe to assume that the strain incompatibility between 
the hard, untempered martensite and relatively soft bainite that induces void formation in a manner akin to dual-phase steels of the type used in automotive applications.

- The films of austenite maintain their stability under the rolling contact circumstances studied here. It is well known that such films are more stable than coarser regions because they contain a greater carbon concentration [37-41] and due to their fine scale [42].

- The hardness of the affected regions of the nanostructured bainite does not change much due to rolling contact fatigue. This too is unlike convention in the 52100 steel, where white-etching regions can form that are softer or harder than the surrounding matrix. The reason is that the fine mixture of bainitic ferrite and austenite does not contain any significant carbide precipitation, whereas in 52100, it is known that cementite can be induced to dissolve in the ferrite due to severe deformation, thus inducing a dramatic change in microstructure. For the same reason, when butterfly-like cracks initiate at inclusions within the bainitic steel, they are not associated with the hard white etching "wings".

Finally, if void formation is promoted by the strain incompatibility arising when the retained austenite is induced to transform into hard martensite, then the structure may not be appropriate for rolling contact applications. On the other hand, the mixture of retained austenite and bainitic ferrite does not suffer from the consequences of carbides (white-etching matter, mechanical tempering, cementite dissolution). Furthermore, when cracks do form by the linking of voids, they exhibit considerable branching, which must delay final fracture. This might explain why nanostructured bainite has been shown in independent work to outperform other microstructures [43], although it is noteworthy that in that study, the carbon concentration was exceptionally large at $1.26 \mathrm{wt} \%$ so that the structures observed were not uniform and contained proeutectoid cementite. Further work comparing carbide-free nanostructured bainite against conventional bearing steels is required to assess whether the failure mechanisms are better or worse than in the latter alloys. 


\section{Acknowledgements}

The authors are thankful to SKF for allowing the use of the RCF test rig. Gratitude is also expressed to Dr. Yan Pei and Dr. Mathew Peet of the Phase Transformations and Complex Properties Group for their help with experimental techniques. Funding by CONACyT, the Cambridge Overseas Trust, and the Roberto Rocca Education Programme is highly appreciated and acknowledged.

\section{References}

\section{References}

[1] F. G. Caballero, H. K. D. H. Bhadeshia, K. J. A. Mawella, D. G. Jones, P. Brown: Materials Science and Technology 2002, vol. 18, pp. 279-284.

[2] F. G. Caballero, H. K. D. H. Bhadeshia: Current Opinion in Solid State and Materials Science 2004, vol. 8, pp. 251-257.

[3] H. K. D. H. Bhadeshia: Proceedings of the Royal Society of London A 2010, vol. 466, pp. 3-18.

[4] H. K. D. H. Bhadeshia: Science and Technology of Advanced Materials 2013, vol. 14, pp. 014202.

[5] F. G. Caballero, C. Garcia-Mateo, M. K. Miller: Journal of Metals 2014, vol. ?, pp. DOI: 10.1007/s11837-014-0908-0.

[6] T. S. Wang, J. Yang, C. J. Shang, X. Y. Li, B. Lv, M. Zhang, F. C. Zhang: Surface \& Coatings Technology 2008, vol. 202, pp. 4036-4040.

[7] P. Zhang, F. C. Zhang, Z. G. Yan, T. S. Wang, L. H. Qian: Wear 2011, vol. 271, pp. 697-704.

[8] A. Leiro, A. Kankanala, E. Vuorinen, B. Prakash: Wear 2011, vol. 273, pp. 2-8.

[9] J. Yang, T. S. Wang, B. Zhang, F. C. Zhang: Wear 2012, vol. 282-283, pp. 81-84. 
[10] A. Leiro, E. Vuorinen, K. G. Sundin, B. Prakash, T. Sourmail, V. Smanio, F. G. Caballero, C. Gracia-Mateo, R. Elvira: Wear 2013, vol. 298-299, pp. 42-47.

[11] T. Sourmail, F. G. Caballero, C. Garcia-Mateo, V. Smanio, C. Ziegler, M. Kuntz, R. Elvira, A. Leiro, E. Vuorinen, T. Teeri: Materials Science and Technology 2013, vol. 29, pp. 1166-1173.

[12] S. D. Bakshi, P. H. Shipway, H. K. D. H. Bhadeshia: Wear 2013, vol. 308, pp. 46-53.

[13] S. D. Bakshi, A. Leiro, B. Prakash, H. K. D. H. Bhadeshia: Wear 2014, vol. 316, pp. 70-78.

[14] X. Y. Feng, F. C. Zhang, J. Kang, Z. N. Yang, X. Y. Long: Materials Science and Technology 2014, vol. ?, pp. DOI 10.1179/1743284713Y.0000000474.

[15] L. C. D. Fielding, E. J. Song, D. K. Han, H. K. D. H. Bhadeshia, D. W. Suh: Proceedings of the Royal Society of London A 2014, vol. 470, pp. 20140108.

[16] M. J. Peet, P. Hill, M. Rawson, S. Wood, H. K. D. H. Bhadeshia: Materials Science and Technology 2011, vol. 27, pp. 119-123.

[17] S. Fujita, S. Matsuoka, T. Murakami: Effect of hydrogen on fatigue behaviour of bearing steel under cyclic torsion with compressive mean stress: in: Mechanics of Materials: Japan Society of Mechanical Engineers, Tokyo, Japan, 2000: pp. 241-243.

[18] K. Burkart, H. Bomas, R. Schroeder, H.-W. Zoch: Rolling contact and compression-torsion fatigue of 52100 steel with special regard to carbide distribution: in: Advances in rolling contact fatigue strength testing and related substitute technologies: ASTM International, West Conshohocken, PA, USA, 2012: pp. 218-236.

[19] Delta Research Corp.: Livonia, Michigan, USA: Ball/Rod RCF Tester Model BR-4 Users Manual 2010,.

[20] D. Glover: A ball-rod rolling contact fatigue tester: in: J. J. C. Hoo (Ed.), Rolling Contact Fatigue Testing of Bearing Steels ASTM STP 771: ASTM International, Philadelphia, USA, 1982: pp. 107-124. 
[21] W. Solano-Alvarez, H. K. D. H. Bhadeshia: Metallurgical \& Materials Transactions A 2014, vol. 45, pp. DOI: 10.1007/s11661-014-2430-y.

[22] K. L. Johnson: Contact Mechanics: Cambridge University Press, Cambridge, U. K., 1985.

[23] D. J. Dyson, B. Holmes: Journal of the Iron and Steel Institute 1970, vol. 208, pp. 469-474.

[24] E. Honda, Z. Nishiyama: Science Reports of Tohoku Imperial University 1932, vol. 21, pp. 299-331.

[25] M. Mata, O. Casals, J. Alcala: International Journal of Solids and Structures 2006, vol. 43, pp. 5994-6013.

[26] H. Styri: Proceedings of ASTM 1951, vol. 51, pp. 682-700.

[27] H. K. D. H. Bhadeshia: Progress in Materials Science 2012, vol. 57, pp. $268-435$.

[28] C. Qing, S. Eryu, Z. Dongmai, G. Juwen, F. Zonghe: Wear 1991, vol. 147, pp. 285-294.

[29] J. Cook, J. E. Gordon, C. C. Evans, D. M. Marsh: Proceedings of the Royal Society of London A 1964, vol. 282, pp. 508-520.

[30] M. A. Greenfield, H. Margolin: Metallurgical Transactions 1972, vol. 3, pp. 2649-2659.

[31] D. L. Steinbrunner, D. K. Matlock, G. Krauss: Metallurgical Transactions A 1988, vol. 19, pp. 579-589.

[32] N. J. Kim, G. Thomas: Metallurgical Transactions A 1981, vol. 12, pp. 483-489.

[33] A. H. Nakagawa, G. Thomas: Metallurgical Transactions A 1985, vol. 16, pp. 831-840.

[34] M. Erdogan: Journal of Materials Science 2002, vol. 37, pp. 3623-3630.

[35] G. Avramovic-Cingara, Y. Ososkov, M. K. Jain, D. S. Wilkinson: Materials Science \& Engineering A 2009, vol. 516, pp. 7-16. 
[36] A. P. Voskamp: Microstructural changes during rolling contact fatigue: Ph.D. thesis: Technical University of Delft 1996,.

[37] S. J. Matas, R. F. Hehemann: TMS-AIME 1961, vol. 221, pp. 179-185.

[38] Y. N. Taran, K. I. Uzlov, A. Y. Kutsov: Journal de Physique IV (Colloque) 1997, vol. 7, pp. C5-429-434.

[39] A. Kutsov, Y. Taran, K. Uzlov, A. Krimmel, M. Evsyukov: Materials Science \& Engineering A 1999, vol. 273-275, pp. 480-484.

[40] H. J. Stone, M. J. Peet, H. K. D. H. Bhadeshia, P. J. Withers, S. S. Babu, E. D. Specht: Proceedings of the Royal Society A 2008, vol. 464, pp. 1009-1027.

[41] F. G. Caballero, M. K. Miller, C. G. Mateo: Materials Science and Technology 2014, vol. 30, pp. 1034-1039.

[42] H. S. Yang, H. K. D. H. Bhadeshia: Scripta Materialia 2009, vol. 60, pp. 493-495.

[43] H. Liu, J. Sun, T. Jiang, S. Guo, Y. Liu: Scripta Materialia 2014, vol. ?, pp. http://dx.doi.org/10.1016/j.scriptamat.2014.07.006. 